\title{
BMJ Open Prospective associations of psychosocial work exposures with mortality in France: STRESSJEM study protocol
}

\author{
Isabelle Niedhammer, ${ }^{1}$ Allison Milner, ${ }^{2}$ Béatrice Geoffroy-Perez, ${ }^{3}$ Thomas Coutrot, ${ }^{4}$ \\ Anthony D LaMontagne, ${ }^{2,5}$ Jean-François Chastang ${ }^{1}$
}

To cite: Niedhammer I, Milner A, Geoffroy-Perez B, et al. Prospective associations of psychosocial work exposures with mortality in France: STRESSJEM study protocol. BMJ Open 2019;9:e031352. doi:10.1136/ bmjopen-2019-031352

- Prepublication history for this paper is available online. To view these files, please visit the journal online (http://dx.doi. org/10.1136/bmjopen-2019031352).

Received 10 May 2019

Revised 03 October 2019

Accepted 08 0ctober 2019

Check for updates

(c) Author(s) (or their employer(s)) 2019. Re-use permitted under CC BY-NC. No commercial re-use. See rights and permissions. Published by BMJ.

${ }^{1}$ INSERM, Univ Angers, Univ Rennes, EHESP, Irset (Institut de recherche en santé, environnement et travail) UMR_S 1085, ESTER Team, Angers, France

${ }^{2}$ Centre for Health Equity, Melbourne School of Population and Global Health, University of Melbourne, Melbourne, Victoria, Australia

${ }^{3}$ Santé publique France, SaintMaurice, France

${ }^{4}$ DARES, Ministère du Travail, Paris, France

${ }^{5}$ Centre for Population Health Research, School of Health \& Social Development, Deakin University, Geelong, Victoria, Australia

Correspondence to Dr Isabelle Niedhammer; isabelle.niedhammer@inserm.fr

\section{ABSTRACT}

Introduction Although evidence has been provided on the associations between psychosocial work exposures and morbidity outcomes in the literature, knowledge appears much more sparse on mortality outcomes. The objective of STRESSJEM is to explore the prospective associations between psychosocial work exposures and mortality outcomes among the national French working population. In this paper, we describe the study protocol, study population, data sources, method for exposure assessment, data analysis and future plans.

Methods and analysis Data sources will include: the data from the national SUMER survey from DARES on the evaluation of psychosocial work exposures and the data from the COSMOP programme from Santé publique France linking job history (DADS data from INSEE) and mortality according to causes of death (data from the national death registry, INSERM-CépiDc). A sample of 1511456 individuals will form the studied prospective cohort for which data are available on both job history and mortality over the period 1976-2002. Psychosocial work exposures will be imputed via a job-exposure matrix using three job title variables that are available in both the SUMER and COSMOP data sets. Our objectives will be to study the associations between various psychosocial work exposures and mortality outcomes. Psychosocial work exposures will include the job strain model factors as well as other psychosocial work factors. Various measures of exposure over time will be used. All-cause and causespecific mortality will be studied.

Ethics and dissemination Both the SUMER survey and the COSMOP programme have been approved by French ethics committees. Dissemination of the study results will include a series of international peer-reviewed papers and at least one paper in French. The results will be presented in national and international conferences. This project will offer a unique opportunity to explore mortality outcomes in association with psychosocial work exposures in a large national representative sample of the working population.

\section{INTRODUCTION}

Psychosocial work exposures are critical considerations in the occupational health of working population in developed countries. Some of these exposures may be highly prevalent among working populations and their burden in terms of costs to society may

\section{Strengths and limitations of this study}

The very large scale of this project is significant given that the few other studies in the area have lacked statistical power, particularly for rare mortality outcomes.

- Major strengths will include: large national representative sample, long follow-up and the lack of response, participation, selection, reporting and attrition bias.

- Psychosocial work exposures will be studied using the validated and recommended questionnaire for the job strain model, other understudied factors will also be explored and various measures of exposure over time will be examined including cumulative exposure.

- Mortality will be studied for all causes together and according to specific causes of death.

- The main limitations will be the following: limited number of available variables, residual confounding bias, use of a job-exposure matrix and small portion of the working population not included.

be substantial. ${ }^{2}$ Previous research provides convincing evidence about the associations between psychosocial work exposures and morbidity outcomes, especially cardiovascular diseases ${ }^{3-6}$ and mental disorders. ${ }^{7-9}$ However, the literature remains sparse on the associations between these exposures and mortality outcomes. To our knowledge, to date, there has been no previous literature review and only one previous metaanalysis using individual-level data from seven cohort studies for the study of the association between work stress and all-cause mortality. ${ }^{10}$

In addition, there are gaps in the knowledge on the effects of psychosocial work exposures on morbidity outcomes. First, most of the literature explored health outcomes that are related to cardiovascular and mental disorders. Studies are lacking on other health outcomes that may be relevant for mortality although some reviews or meta-analyses suggested that psychosocial work exposures 
may have an impact on other health outcomes, such as type 2 diabetes, ${ }^{11-13}$ for example. Second, most previous studies have focused on the exposures from the job strain model, ${ }^{14}$ that is, psychological demands, decision latitude, social support and the combined exposures of job strain (high demands and low latitude) and iso-strain (job strain and low support). However, the psychosocial work environment contains a far greater variety of exposures than expressed in this model alone. Consequently, there is a need to broaden the study of the psychosocial work environment to other exposures that are not covered by the job strain model. Regarding exposure again, there is also a lack of studies exploring the temporal associations between exposure and outcome (eg, effects of cumulative exposure), as most prospective studies have relied on a single evaluation of exposure at baseline and not on integrated measures of exposure over long periods of time. Repeated measures within individuals are needed to better understand long-term exposure-outcome associations.

Studies on the associations between psychosocial work exposures and mortality are difficult to perform. Indeed, prospective studies need large sample sizes and long follow-up to be able to provide meaningful results, because mortality is a rather rare outcome in working age populations. Moreover, case-control studies of mortality are also challenging in that retrospective evaluation of exposure may be difficult to reconstruct. Linkages between various data sources which can provide both occupational exposures and mortality may be the most suitable approach to alleviate some of these difficulties. Another pertinent approach may be to apply a job-exposure matrix (JEM) that uses job title as a proxy for exposure.

The objectives of the STRESSJEM project will be to explore the prospective associations between psychosocial work exposures and mortality. In more detail, the aims of this project will be:

- to study all-cause and cause-specific mortality outcomes in association with psychosocial work exposures,

- to explore the exposures from the job strain model but also other less studied exposures, and

- to examine various measures of exposure over time.

\section{METHODS AND ANALYSIS}

The STRESSJEM project will be based on two large data sets: the first one is the data set of the national SUMER (SUrveillance Médicale des Expositions aux Risques professionnels) survey set up by DARES (Direction de l'Animation de la Recherche, des Etudes et des Statistiques) of the French Ministry of Labour and the second one is the data set of the COSMOP (COhorte de Surveillance de la MOrtalité selon l'activité Professionnelle) programme set up by Santé publique France. Both the SUMER survey and the COSMOP programme were approved by French ethics committees (Commission Nationale de l'Informatique et des Libertés and Conseil National de l'Information Statistique).
Study population and data source for job history and mortality The COSMOP data set relies on the linkage of the DADS (Déclaration Annuelle des Données Sociales) panel with the medical causes of death of the French national death registry (INSERM-CépiDc - Institut National de la Santé Et de la Recherche Médicale-Centre d'épidémiologie et de recherche sur les causes médicales de Décès). The DADS panel is a random sample (1/24th) of the population, set up by INSEE (Institut National de la Statistique et des Etudes Economiques), for whom administrative data, called Annual Declarations of Social Data (DADS), were accumulated over time. These data are mandatorily collected annually by French companies on their employees for social, tax and statistics administrations. The population covered by the DADS represents about $80 \%$ of all jobs in France, as some sectors/workers are not included in the scope of the DADS such as selfemployed workers, agricultural workers/employees, employees of some public sectors and employees of household activities and extra-territorial organisations. The data used for this project will include, for all jobs held during the 1976-2002 period: date of start and end of job, occupation and economic activity of the company, both coded using the standard French classifications (PCS-Professions et Catégories Socioprofessionnelles and NAF-Nomenclature d'Activités Française) and company size. For the COSMOP programme, this data set was linked to the mortality data and then to causes of death recorded by the French national death registry (INSERMCépiDc) over the period 1976-2005. The causes of death are coded using the International Classification of Diseases (ICD). INSERM-CépiDc has been in charge of the national causes of death statistics in France for a very long time. Cause of death certification and codification practices follow common recommendations and guidelines in the European Community. Nevertheless, some biases are still possible, for example, the underestimation of some causes of death, and this issue will be discussed in depth in the forthcoming studies for specific causes of death. Thus, the COSMOP data set is a national representative prospective cohort of 1511456 individuals, aged 16 or greater, born in France, followed from 1 January 1976 to 31 December 2002 for both their job history and mortality.

\section{Study population and data source for exposure assessment}

JEMs will be used to provide exposure estimates for all jobs an individual may have held, as recorded in the COSMOP data set. These JEMs will be based on the SUMER data set. The SUMER survey is a national periodical survey on working conditions of French employees. The purpose of the SUMER survey is to provide a comprehensive overview of all kinds of occupational hazards (physical, chemical, biological, biomechanical and psychosocial) in France. It relies on a large network of occupational physicians who collect the data for a random sample of employees. In France, all employees are covered by occupational medicine and have a periodical medical examination with an 
occupational physician. In 2003, the SUMER survey was the first French national survey that evaluated psychosocial work exposures according to the job strain model, using the validated and recommended questionnaire, ${ }^{15} 16$ as well as other psychosocial work exposures. The sample included a large national representative sample of the French working population of employees composed of 24486 individuals (response rate: 96.5\%). Details on the 2003 SUMER survey can be found elsewhere. ${ }^{17-19}$ Using the data from the 2003 SUMER survey, a first JEM was constructed and validated for the job strain model factors, that is, psychological demands, decision latitude and social support, ${ }^{20}$ and other JEMs will be constructed and studied for other psychosocial work exposures which are: low reward, job insecurity, temporary employment, long working hours, atypical work schedules, low predictability and workplace violence. The methods of the JEM construction based on both a segmentation method (CART) and cross-validation were described extensively in a previous publication ${ }^{20}$ and will also be used for the construction of new JEMs. The JEM provides exposure estimates using three variables of job title: occupation and economic activity of the company both coded using the standard French classifications (PCS and NAF) and company size for men and women separately. The two first hierarchical levels of the PCS classification were used to code occupation (ie, more than 30 occupation groups) and the five hierarchical levels of the NAF classification were used to code economic activity (ie, more than 700 economic activity groups). These exposure estimates will be imputed in the COSMOP data set using the same three variables of job title, for all men and women of the data set, providing measures of exposures for each job held during the 1976-2002 period.

\section{Mortality outcomes}

All-cause mortality will be studied, as well as mortality according to specific causes of death as coded using the International Classification of Diseases (ICD). Particular attention will be given to mortality for cardiovascular diseases and suicide, which have been widely explored and demonstrated in the literature on morbidity outcomes for cardiovascular $^{3-6}$ and mental health. ${ }^{7-9}$ Other causes of death will also be investigated. Some meta-analyses have explored associations between psychosocial work exposures (mainly job strain) and rarely studied morbidity outcomes such as cancer, digestive or respiratory diseases but provided inconclusive results. ${ }^{21-24}$ The STRESSJEM project will be able to provide results on mortality for these particular diseases and confirm or not the absence of significant associations.

\section{Psychosocial work exposures}

The main and first studies will examine the exposures from the job strain model, that is, the factors of psychological demands, decision latitude, social support and the combined variables of job strain and iso-strain. These factors have been found to be risk factors for various health outcomes in morbidity studies. As evidence, all reviews and meta-analyses quoted above examined the job strain model and its components. ${ }^{3-9}$ Other psychosocial work exposures will also be studied, such as factors which have been found to be associated with various morbidity outcomes and highlighted in reviews or metaanalyses, such as those related to job insecurity, ${ }^{25-27}$ temporary employment, ${ }^{28}$ long working hours ${ }^{29-32}$ and workplace violence. ${ }^{33} 34$ Other understudied exposures will be considered such as lack of predictability. ${ }^{35}$

\section{Calculation of exposure over time}

Because there has been only limited research on the temporal associations between exposure and health or mortality outcomes, three time-varying measures of exposure will be constructed using all jobs held within the 1976-2002 period, with the results of parallel analyses cross-compared:

1. Current exposure: the exposure will be related to the exposure of the job at time $i$, and if an individual is not working in the DADS scope (ie, unemployed, retired, or working outside the DADS scope) at time $\mathrm{i}$, the information will be midcensoring, which means that only time periods with a job in the DADS scope will be considered (see also statistical methods section).

2. Cumulative exposure using past and current exposures of all jobs until time $i$ : an average measure at time i will be calculated using the estimates of exposure and the time spent in all jobs up to and including time i. This measure will allow to take account of all information available for each individual, allowing time variation in the total time spent in jobs between individuals. If an individual is not working in the scope of the DADS, then the last estimate of exposure will be carried forward until the next job, death or end of follow-up. Such a measure of cumulative exposure makes the assumption of cumulative and irreversible effects.

3. Recency-weighted cumulative exposure using both past and current exposures and the time elapsed since the exposure: this measure will allow to use weights representing the relative importance of exposure as a function of the time elapsed since exposure, with higher weights assigned to more recent exposures. ${ }^{36}$ We will use the assumption from a previous study ${ }^{37}$ to define the weights and will assume that psychosocial work exposure effects would persist for a period of up to 5 years after the end of exposure and thus would decrease linearly over a 5 -year period to be null after 5 years.

As cumulative exposure and recency-weighted cumulative exposure are time-weighted average measures, the unit of these two measures will be the same as the unit of the current exposure measure (eg, a score with the same range).

We will also attempt to investigate and construct other measures of exposure over time and compare the results, such as, for example, absolute duration of exposure or peak of exposure among the subsample of those who 
were working during the same length of time, without any interruption, for example, within a period of 5 or 10 years.

\section{Statistical methods}

The HR of mortality will be estimated according to the studied exposures using Cox proportional hazards models. The studied exposures will be time-dependent variables. Data for each individual will be converted into time intervals, each time interval corresponding to a job or a period outside the DADS scope. Each time interval will have start and stop dates. Within each time interval in a given job, the exposures will be kept constant, based on the corresponding estimates derived from the JEM. Age will be used as the time scale. Calendar time will be included as an adjustment variable. Four occupational variables related to biomechanical, physical, chemical and biological exposures imputed through JEMs using the three job title variables of occupation, economic activity and company size will also be included as adjustment variables. We will use a model with delayed entry. Individuals will enter the cohort on 1 January 1976 if they already have a job or when they start a first job within the 1976-2002 period.

For the three exposure measures described above, we will use mortality until the end of last job, to study mortality during time intervals with a job in the DADS scope (called 'on-the-job' mortality); thus in this analysis, the follow-up will end at the time of death or at the end date of the last job within the 1976-2002 period, or at the end of follow-up (31 December 2002) if still working at this time, whichever comes first.

For the two measures of cumulative exposure, as delayed effects may be expected, a second analysis will be performed in which the follow-up will end at the time of death or on 31 December 2002, whichever comes first.

Comparisons between the models according to the exposure measure will be performed to identify the model with the best relative quality using Akaike Information Criterion (AIC).

Finally, we will calculate the fractions of mortality attributable to the studied psychosocial work exposure in France with Pe being the prevalence of exposure (proportion of the population exposed) and HR being the HR for mortality associated with exposure ${ }^{38}$ :

$\mathrm{AF}=\mathrm{Pe}(\mathrm{HR}-1) /[1+\mathrm{Pe}(\mathrm{HR}-1)]$.

Attributable fractions (AFs) produce an estimate of the fraction of cases that is 'attributable to an exposure in a population and that would not have been observed if the exposure had been non-existent'. ${ }^{39}$ Pe will be estimated by the weighted prevalence of exposure using the data of the SUMER survey. HR will be estimated by the results from the present project. Simulation-modelling techniques will be used to obtain CIs for AFs, as previously described. ${ }^{40}$ The annual number of deaths attributable to exposure among the French population of working age will be calculated by applying the estimated $\mathrm{AF}$ on the total number of deaths in the French population from the data of INSERM-CépiDc.

All analyses will be performed separately for men and women, and on the total sample of men and women to test gender-related interactions.

\section{Sensitivity analyses}

Sensitivity analyses will be performed to test the robustness of the results:

- Using scores for the measure of exposure instead of binary variables

- Performing additional adjustment for the large groups of occupations (the first level of the standard French classification)

- Imputing the lowest level of exposure in case of multiple job-holder instead of the highest level of exposure (only $3 \%$ of the sample had more than one job at the same time)

- Studying mortality until 2005 as mortality data were collected until the end of 2005 whereas job history is available until 2002 only.

\section{Planned start and end dates for the study}

The study has already begun with the construction, validation and publication of a first JEM for the job strain model factors. ${ }^{20}$ The study is likely to end at the end of 2020 or mid-2021 at the latest.

\section{First findings}

The studied sample includes 1511456 individuals, including 806513 men and 704943 women. The mean age at entrance in the cohort was 28 years for men and 27 for women, and the mean age at the end of follow-up (ie, 31 December 2002 or at the time of death) was 45 years for men and 44 for women, that is, a mean follow-up duration of 17 years. Within the 1976-2002 period, 89 639 deaths occurred among men and 29218 occurred among women.

Among the total sample of 1511456 individuals, we have not been able to impute the exposures of the job strain model from the JEM for 15124 individuals (ie, $1 \%$ ) because of missing data for one or more job title variables, and/or start or end dates of job. The sample has thus been reduced to 1496332 individuals, including 798547 men and 697785 women. The description of the sample for the job strain model exposures of the first and last jobs held within the 1976-2002 period is presented in table 1 . Women were more likely to be exposed to high demands, low latitude, low support, job strain and isostrain than men. Men were more likely to be exposed to low strain (low demands and high latitude). Changes over time were observed as the prevalence of high psychological demands increased but the prevalence of exposure to low decision latitude, low social support, job strain and iso-strain decreased over the study time period $(\mathrm{p}<0.001)$.

\section{DISCUSSION}

In the STRESSJEM project, we aim to explore the prospective associations between psychosocial work exposures 
Table 1 Description of the job strain model factors for the first and last jobs held within the 1976-2002 period among men and women

\begin{tabular}{|c|c|c|c|c|c|c|}
\hline \multirow[b]{2}{*}{ 1976-2002 } & \multicolumn{3}{|l|}{ First job } & \multicolumn{3}{|l|}{ Last job } \\
\hline & $\begin{array}{l}\text { Men } \\
\mathrm{n}=798547\end{array}$ & $\begin{array}{l}\text { Women } \\
\mathrm{n}=697785\end{array}$ & $P$ value & $\begin{array}{l}\text { Men } \\
n=798547\end{array}$ & $\begin{array}{l}\text { Women } \\
\mathrm{n}=697785\end{array}$ & $P$ value \\
\hline Scores* & Mean & Mean & & Mean & Mean & \\
\hline $\begin{array}{l}\text { Psychological demands } \\
\text { (min: 9, max: 36) }\end{array}$ & 21.12 & 21.45 & 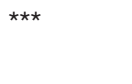 & 21.42 & 21.68 & *** \\
\hline $\begin{array}{l}\text { Decision latitude } \\
\text { (min: 24, max: 96) }\end{array}$ & 69.19 & 66.37 & *** & 71.15 & 67.60 & $\star \star \star *$ \\
\hline $\begin{array}{l}\text { Social support } \\
\text { (min: 8, max: 32) }\end{array}$ & 23.71 & 23.61 & *** & 23.76 & 23.67 & *** \\
\hline Exposures & $\%$ & $\%$ & & $\%$ & $\%$ & \\
\hline High psychological demands $†$ & 43.75 & 57.07 & 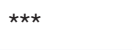 & 54.93 & 61.40 & 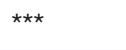 \\
\hline Low decision latitude $†$ & 50.78 & 54.31 & *** & 39.18 & 48.22 & *** \\
\hline Low social support† & 49.52 & 64.67 & 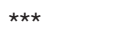 & 39.92 & 55.99 & 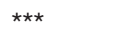 \\
\hline Job strain & 16.30 & 25.70 & 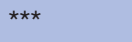 & 12.84 & 22.96 & $\star \star \star ~$ \\
\hline Isostrain & 11.03 & 25.69 & *** & 9.52 & 22.91 & 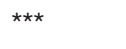 \\
\hline Karasek’s quadrantsł & & & $\star \star \star$ & & & $\star \star \star$ \\
\hline Active job & 27.45 & 31.38 & & 42.08 & 38.44 & \\
\hline Low strain & 21.77 & 14.31 & & 18.73 & 13.34 & \\
\hline Passive job & 34.48 & 28.61 & & 26.34 & 25.26 & \\
\hline High strain & 16.30 & 25.70 & & 12.84 & 22.96 & \\
\hline
\end{tabular}

$P$ value: test for comparison between men and women (t-test for mean scores, $\chi^{2}$ test for $\%$ of exposure). ${ }^{* * *} \mathrm{p}<0.001$

${ }^{*}$ The higher the score, the higher the demands, latitude and support

†Score dichotomised at the median of the distribution for the first job in the total sample

fHigh strain (high demands and low latitude), low strain (low demands and high latitude), passive job (low demands and low latitude) and active job (high demands and high latitude)

and mortality outcomes in a large national representative sample of the French working population of employees. Various types of exposures and various measures of exposure over time will be studied. The outcomes will be all-cause mortality and cause-specific mortality. Taking advantage of two separate and large data sets that will be used and linked using JEMs, we will also be able to estimate fractions of mortality attributable to psychosocial work exposures.

\section{Strengths and limitations}

Many strengths of our study deserve to be mentioned. The studied sample will be very large and by far the largest to date in the literature on this topic. The project will rely on national representative data making the generalisation of the results possible to the target population. Furthermore, men and women will be studied separately and genderrelated interactions will be tested, following good practice in the field of occupational health. ${ }^{30}$ The follow-up for both exposure and outcome will be very long, up to 26 years. As the project will be based on routine data, there will be no response, participation or selection bias. Likewise, there will be no individuals lost to follow-up and consequently no attrition bias. There will be no reporting bias, as data for mortality is collected routinely and exposure will be derived from JEMs constructed using another national representative data set. Mortality is an objective outcome, and is provided by the French national death registry. An additional strength will be the study of various measures of exposure over time. Sensitivity analyses will be performed to explore the robustness of the results. Finally, to our knowledge, it will be the first study to provide comparison between various measures of exposure in relation to time, and also one of the first studies to give estimates of the fractions of mortality attributable to psychosocial work exposures.

A number of limitations should, however, be acknowledged. As the project will rely on routine data, the number of variables will be limited and confounding bias cannot be ruled out. Age will be taken into account as the time scale in the Cox models. The available adjustment/stratification variables will be gender, calendar time and other occupational exposures (biomechanical, physical, chemical and biological exposures). These last adjustment variables may be a way to control for other occupational exposures at the workplace, and indirectly for social position as these exposures may be strongly 
related to socioeconomic status. Occupation will be taken into account as adjustment variable in the sensitivity analysis only. Indeed, because exposure assessment will be derived from JEMs using occupation among the job title variables, adjusting for occupation can be considered as an overadjustment. As we will use JEMs, there will also be the inherent limitations of this method, that is, no within group variance, potential non-differential misclassification and lack of precision in the evaluation of exposure. These limitations tend to lead to a reduced statistical power and to an underestimation of the association between exposure and outcome (bias towards the null hypothesis), suggesting that our results would be conservative. The DADS scope covers $80 \%$ of jobs in France, as the other $20 \%$ are covered by other systems related to selfemployed workers, public sector employees, etc. Consequently, there will be missing information about exposure for any job not in the DADS scope and the measures of cumulative exposures would be affected slightly by this absence of information. There will also be a time lag between exposure assessment (SUMER data, 2003) and the time period of the job history data (COSMOP data, 1976-2002). The 2003 SUMER survey was the first edition of the periodical SUMER survey to include the validated and recommended questionnaire of the job strain model factors among the whole national French working population. We would argue that our exposure estimates will be reasonably representative of the whole study period. We showed in a previous publication ${ }^{20}$ that there may be changes in JEMs for the job strain model factors over the 2003-2010 period. These changes affected more the absolute values of exposure estimates than the relative position (rank) of occupations, economic activities and company sizes. In addition, we may assume that these changes may be more marked during economic crisis (such as the 2008 crisis) and for specific exposures (job insecurity for example). As some data for other psychosocial work exposures (workplace violence for example) may be available before 2003 (in the 1994 SUMER data, for example), we will be able to perform a sensitivity analysis to check the validity of our assumption. Finally, as our study will be based on the 1976-2002 time period, it will not be possible to evaluate exposures over the complete working life course.

\section{Ethics and dissemination}

Ethical permissions were granted by French ethics committees: Commission Nationale de l'Informatique et des Libertés (no 762430V1 and no 04-1274) and Conseil National de l'Information Statistique (no 2009X705TV). A series of papers will be planned on the prospective associations between psychosocial work exposures and mortality outcomes, and will be submitted to international peer-reviewed scientific journals. These papers will offer the results of the studies according to the studied exposure and outcome. At least one paper will be published in French for a French audience. The results will be presented in national and international conferences.

\section{CONCLUSION AND POLICY IMPLICATIONS}

We believe that the STRESSJEM project will substantially expand our understanding of the associations between psychosocial work exposures and mortality outcomes. Despite the presence of some limitations, the project will have a large number of strengths including very large sample size, long follow-up and the absence of response, participation, selection, reporting and attrition biases and can be considered as one of the major projects on this topic to date. Finally, to help application of findings to policy and practice, this project will also provide the first estimates of the burden of psychosocial work exposures on mortality in the working population via the calculation of AFs.

Acknowledgements The authors thank the members of DARES (French ministry of labour), all the occupational physicians and 'médecins inspecteurs régionaux du travail', and all the employees who participated to the SUMER survey. The authors thank Catherine Buisson, Laurence Chérié-Challine and Pascal EmpereurBissonnet at Santé publique France (Direction Santé Travail) for the access to the COSMOP database. The authors also thank all people and public institutions who contributed directly or indirectly to the COSMOP database, especially INSEE and INSERM-CépiDc.

Contributors IN is the principal investigator who designed the project and drafted and revised the manuscript. JFC and AM made substantial contributions to the design of the project. JFC, AM and ADL were involved in revising the manuscript critically for important scientific content. JFC is in charge of all statistical analyses. BGP is in charge of the COSMOP data set at Santé publique France and TC is in charge of the SUMER data set at DARES; they both provided technical help on these data sets. All authors have read, reviewed and approved the final version of the manuscript.

Funding This study was supported by ANSES (EST-2016/1/49).

Competing interests None declared.

Patient consent for publication Not required.

Provenance and peer review Not commissioned; externally peer reviewed.

Open access This is an open access article distributed in accordance with the Creative Commons Attribution Non Commercial (CC BY-NC 4.0) license, which permits others to distribute, remix, adapt, build upon this work non-commercially, and license their derivative works on different terms, provided the original work is properly cited, appropriate credit is given, any changes made indicated, and the use is non-commercial. See: http://creativecommons.org/licenses/by-nc/4.0/.

Author note We wish to dedicate this paper to the memory of our highly valued colleague, Allison Milner, who died tragically and prematurely in August 2019.

\section{REFERENCES}

1 Hassard J, Teoh KRH, Visockaite G, et al. The cost of work-related stress to society: a systematic review. J Occup Health Psychol 2018;23:1-17.

2 Sultan-Taïeb H, Chastang J-F, Mansouri M, et al. The annual costs of cardiovascular diseases and mental disorders attributable to job strain in France. BMC Public Health 2013;13:748.

3 Fransson El, Nyberg ST, Heikkilä K, et al. Job strain and the risk of stroke: an individual-participant data meta-analysis. Stroke 2015;46:557-9.

4 Huang Y, Xu S, Hua J, et al. Association between job strain and risk of incident stroke: a meta-analysis. Neurology 2015;85:1648-54.

5 Kivimäki M, Nyberg ST, Batty GD, et al. Job strain as a risk factor for coronary heart disease: a collaborative meta-analysis of individual participant data. Lancet 2012;380:1491-7.

6 Xu S, Huang Y, Xiao J, et al. The association between job strain and coronary heart disease: a meta-analysis of prospective cohort studies. Ann Med 2015;47:512-8.

7 Madsen IEH, Nyberg ST, Magnusson Hanson LL, et al. Job strain as a risk factor for clinical depression: systematic review and metaanalysis with additional individual participant data. Psychol Med 2017;47:1342-56. 
8 Milner A, Witt K, LaMontagne AD, et al. Psychosocial job stressors and suicidality: a meta-analysis and systematic review. Occup Environ Med 2018;75:245-53.

9 Theorell T, Hammarström A, Aronsson G, et al. A systematic review including meta-analysis of work environment and depressive symptoms. BMC Public Health 2015;15:738.

10 Kivimäki M, Pentti J, Ferrie JE, et al. Work stress and risk of death in men and women with and without cardiometabolic disease: a multicohort study. Lancet Diabetes Endocrinol 2018;6:705-13.

11 Cosgrove MP, Sargeant LA, Caleyachetty R, et al. Work-Related stress and type 2 diabetes: systematic review and meta-analysis. Occup Med 2012;62:167-73.

12 Nyberg ST, Fransson El, Heikkilä K, et al. Job strain as a risk factor for type 2 diabetes: a pooled analysis of 124,808 men and women. Diabetes Care 2014;37:2268-75.

13 Sui $\mathrm{H}$, Sun $\mathrm{N}$, Zhan L, et al. Association between work-related stress and risk for type 2 diabetes: a systematic review and meta-analysis of prospective cohort studies. PLoS One 2016;11:e0159978.

14 Karasek R, Brisson C, Kawakami N, et al. The job content questionnaire (JCQ): an instrument for internationally comparative assessments of psychosocial job characteristics. J Occup Health Psychol 1998;3:322-55.

15 Niedhammer I. Psychometric properties of the French version of the Karasek job content questionnaire: a study of the scales of decision latitude, psychological demands, social support, and physical demands in the GAZEL cohort. Int Arch Occup Environ Health 2002;75:129-44.

16 Niedhammer I, Ganem V, Gendrey L, et al. Propriétés psychométriques de la version française des échelles de la demande psychologique, de la latitude décisionnelle et du soutien social du " Job Content Questionnaire " de Karasek : résultats de l'enquête nationale SUMER. Santé Publique 2006;18:413-27.

17 Niedhammer I, Chastang J-F, David S. Importance of psychosocial work factors on general health outcomes in the National French SUMER survey. Occup Med 2008;58:15-24.

18 Niedhammer I, Chastang J-F, David S, et al. The contribution of occupational factors to social inequalities in health: findings from the National French SUMER survey. Soc Sci Med 2008;67:1870-81.

19 Niedhammer I, Chastang J-F, Levy D, et al. Study of the validity of a job-exposure matrix for psychosocial work factors: results from the National French SUMER survey. Int Arch Occup Environ Health 2008;82:87-97.

20 Niedhammer I, Milner A, LaMontagne AD, et al. Study of the validity of a job-exposure matrix for the job strain model factors: an update and a study of changes over time. Int Arch Occup Environ Health 2018;91:523-36.

21 Heikkilä K, Madsen IEH, Nyberg ST, et al. Job strain and the risk of inflammatory bowel diseases: individual-participant meta-analysis of 95000 men and women. PLoS One 2014;9:e88711.

22 Heikkilä K, Madsen IEH, Nyberg ST, et al. Job strain and the risk of severe asthma exacerbations: a meta-analysis of individualparticipant data from 100000 European men and women. Allergy 2014;69:775-83.

23 Heikkilä K, Madsen IEH, Nyberg ST, et al. Job strain and COPD exacerbations: an individual-participant meta-analysis. Eur Respir J 2014;44:247-51.
24 Heikkilä K, Nyberg ST, Theorell T, et al. Work stress and risk of cancer: meta-analysis of 5700 incident cancer events in 116,000 European men and women. BMJ 2013;346:f165.

25 Ferrie JE, Virtanen M, Jokela M, et al. Job insecurity and risk of diabetes: a meta-analysis of individual participant data. CMAJ 2016;188:E447-55.

26 Kim TJ, von dem Knesebeck O. Perceived job insecurity, unemployment and depressive symptoms: a systematic review and meta-analysis of prospective observational studies. Int Arch Occup Environ Health 2016;89:561-73.

27 Virtanen M, Nyberg ST, Batty GD, et al. Perceived job insecurity as a risk factor for incident coronary heart disease: systematic review and meta-analysis. BMJ 2013;347:f4746.

28 Virtanen M, Kivimäki M, Joensuu M, et al. Temporary employment and health: a review. Int J Epidemiol 2005;34:610-22.

29 Kivimäki M, Jokela M, Nyberg ST, et al. Long working hours and risk of coronary heart disease and stroke: a systematic review and metaanalysis of published and unpublished data for 603,838 individuals. Lancet 2015;386:1739-46.

30 Kivimäki M, Virtanen M, Kawachi I, et al. Long working hours, socioeconomic status, and the risk of incident type 2 diabetes: a meta-analysis of published and unpublished data from 222120 individuals. Lancet Diabetes Endocrinol 2015;3:27-34.

31 Virtanen M, Kivimäki M. Long working hours and risk of cardiovascular disease. Curr Cardiol Rep 2018;20:123.

32 Virtanen M, Jokela M, Madsen IE, et al. Long working hours and depressive symptoms: systematic review and meta-analysis of published studies and unpublished individual participant data. Scand $J$ Work Environ Health 2018;44:239-50.

33 Leach LS, Poyser C, Butterworth P. Workplace bullying and the association with suicidal ideation/thoughts and behaviour: a systematic review. Occup Environ Med 2017;74:72-9.

34 Verkuil B, Atasayi S, Molendijk ML. Workplace bullying and mental health: a meta-analysis on cross-sectional and longitudinal data. PLoS One 2015;10:e0135225.

35 Väänänen $A$, Koskinen $A$, Joensuu $M$, et al. Lack of predictability at work and risk of acute myocardial infarction: an 18-year prospective study of industrial employees. Am J Public Health 2008;98:2264-71.

36 Sylvestre M-P, Abrahamowicz M. Flexible modeling of the cumulative effects of time-dependent exposures on the hazard. Stat Med 2009;28:3437-53.

37 Amick BC, McDonough P, Chang $\mathrm{H}$, et al. Relationship between allcause mortality and cumulative working life course psychosocial and physical exposures in the United States labor market from 1968 to 1992. Psychosom Med 2002;64:370-81.

38. Levin ML. The occurrence of lung cancer in man. Acta Unio Int Contra Cancrum 1953;9:531-41.

39 Nurminen M, Karjalainen A. Epidemiologic estimate of the proportion of fatalities related to occupational factors in Finland. Scand J Work Environ Health 2001;27:161-213.

40 Niedhammer I, Sultan-Taïeb H, Chastang J-F, et al. Fractions of cardiovascular diseases and mental disorders attributable to psychosocial work factors in 31 countries in Europe. Int Arch Occup Environ Health 2014;87:403-11. 